\title{
STRATEGI PEMASARAN USAHA MIKRO CITRONG (CHEESE STICKTERONG) KELOMPOK WANITA TANI MENTARI BINAAN ORGANISASI IAAS LC UNPAD
}

\section{CITRONG MICRO BUSINESS MARKETING STRATEGY (CHEESE STICK TERONG) GROUP OF TANI MENTARI WOMEN Fostered by IAAS LC UNPAD ORGANIZATION}

\author{
Lusi Wulan Safitri \\ Universitas Padjadjaran \\ Email: lusiwulansafitri@gmail.com \\ Lucyana Trimo \\ Universitas Padjadjaran \\ Email: lucy.trimo@gmail.com
}

\begin{abstract}
ABSTRAK
Desa Genteng memiliki potensi pada sektor pertanian yang didominasi oleh berbagai komoditas sayuran, salah satunya adalah terong. Program Village Concept Project yang dilaksanakan pada tahun 2016 telah berhasil mewujudkan kolaborasi antara IAAS LC Unpad dan Kelompok Wanita Tani Mentari, yaitu membuat produk snack berbahan dasar terong berupa Citrong. Mengembangkan usaha mikro Citrong tidak selamanya berjalan dengan lancar, dimana Kelompok Wanita Tani Mentari masih dihadapkan pada permasalahan pemasaran. Sehingga perlu dirumuskan strategi pemasaran yang tepat. Tujuan dari penelitian ini adalah merumuskan strategi pemasaran untuk mengembangkan usaha mikro Citrong bagi Kelompok Wanita Tani Mentari. Penelitian ini menggunakan desain kualitatif dengan teknik studi kasus. Analisis data yang digunakan adalah analisis matriks IFAS, EFAS, IE, SWOT dan QSPM. Hasil penelitian ini adalah usaha mikro Citrong berada pada sel II (posisi internal yang rata-rata dan posisi eksternal yang kuat) yang menunjukkan jenis strategi Tumbuh dan Kembangkan. Jadi, strategi pemasaran yang dapat diterapkan adalah strategi intensif seperti penetrasi pasar, pengembangan pasar, dan pengembangan produk atau strategi terintegrasi seperti integrasi ke belakang, integrasi ke depan dan integrasi horisontal.
\end{abstract}



Jurnal Perilaku

Dan Strategi

Bisnis

Vol.8 No.2, 2020

Hal. $94-107$

Kata Kunci: citrong, strategi pemasaran, usaha mikro

\begin{abstract}
Genteng village's potential in agriculture sector is dominated by various vegetables commodities, one of which is eggplant. The Village Concept Program that was held in 2016 have been successful on creating a collaboration between IAAS LC Unpad and Kelompok Wanita Tani Mentari, which is a snack called Citrong with eggplant as it's main ingredient. The development of Citrong as a micro business doesn't always go as planned, because
\end{abstract}


Kelompok Wanita Tani Mentari still can't market this product. So, marketing strategy is needed. This research aims to create a marketing strategy of Citrong micro business for Kelompok Wanita Tani Mentari. This research use qualitative design with study case as research technique. IFAS, EFAS, IE, and QSPM matrix are used for data analysis. The results of this research is micro business of Citrong in cell II (average internal position and high external position) which shows the type of strategy "Growth and Build". So, marketing strategy that can be applied are intensive strategies such as market penetration, market development, and product development or integrated strategies such as backward integration, forward integration and horizontal integration.

Keywords: citrong, marketing strategy, micro business

\section{PENDAHULUAN}

Negara Indonesia dikategorikan sebagai negara berkembang. Upaya dalam membangun perekonomiannya, maka diperlukan adanya kelompok masyarakat yang tergabung dalam Triple Helix salah satunya ialah akademisi (Fakhrul, 2018). Salah satu cara dalam membangun perekonomian Indonesia adalah melalui pembentukan program pemberdayaan desa untuk menjadikan desa sebagai pusat kegiatan ekonomi (Wulandari \& Sumodiningrat, 2016). Negara-negara di Eropa, Amerika, dan Asia menjadikan UMKM sebagai pilar ketangguhan dalam pembangunan ekonomi nasionalnya (Wilantara \& Rully, 2016). Oleh sebab itu, membangun Indonesia dari desa merupakan strategi yang tepat dengan mengajak, membangiktkan, dan memperbanyak masyarakat desa melalui UMKM dengan melibatkan peran dari akademisi.

Peran akademisi, yaitu menghasilkan berbagai temuan yang inovatif dengan memanfaatkan sumber daya, ilmu pengetahuan, dan teknologi. Salah satunya sudah dilakukan oleh organisasi IAAS (International Association of Students in Agricultural and Related Sciences) yang terdapat di delapan universitas di Indonesia. Organisasi tersebut membentuk program bina desa yang dinamakan Village Concept Project, program ini menerapkan konsep entrepreneur, education, dan empowerment. Hasil dari program tersebut adalah terjalinnya kolaborasi dalam membangun usaha berbasis kegiatan sosial bersama masyarakat desa, yaitu dengan melihat potensi dan kendala sumber daya alam pertanian yang dimiliki desa dari setiap kota/kabupaten di universitas masing-masing. Berikut merupakan produk program Village Concept Project tahun 2016-2019 pada Tabel 1. Adapun diantara delapan produk tersebut, brand Citrong dikategorikan sebagai "best product" dengan indikator pemasaran dan inovasi produk terbaik pada acara $24^{\text {th }}$ IAAS National Congress tahun 2017 di IAAS LC Universitas Mataram. Citrong merupakan produk dari IAAS LC Unpad yang berasal dari Desa Genteng, Kecamatan Sukasari, Kabupaten Sumedang, Jawa Barat.

Tabel 1. Produk Program Village Concept Project Tahun 2016-2019

\begin{tabular}{ll}
\hline \multicolumn{1}{c}{ IAAS Local Committee } & \multicolumn{1}{c}{ Brand } \\
\hline Unpad (Sumedang) & Citrong (Cheese Stick Terong) \\
Undip (Semarang) & Chocoped (Coklat Jelly Jahe) \\
UNS (Solo) & Kumbang Buah (Kue Tambang Buah) \\
IPB (Bogor) & Mutello (Muffin Ubi) \\
UGM (Yogyakarta) & Tortiaas (Chips Jagung) \\
UB (Malang) & Madutrigona (Madu Murni) \\
Unlam (Banjarmasin) & Teh Baday (Teh Celup Bawang Dayak) \\
Unram (Mataram) & Dolpis (Dodol Pisang) \\
Sumber: IAAS Indonesia National Committe, 2018/2019
\end{tabular}


Terjadinya harga jual terong yang sangat rendah pada saat panen raya, mengakibatkan petani memilih untuk membagikan terong secara gratis atau dijadikan pakan ternak (Aqil, 2018). Melihat kendala tersebut, maka pada tahun 2016 IAAS LC unpad melalui program Village Concept Project berinisiatif untuk mengadakan kegiatan pengolahan pangan yang dilakukan oleh warga setempat secara berkelanjutan. Pengolahan tersebut mengikutsertakan kaum wanita Desa Genteng yang tergabung dalam organisasi Kelompok Wanita Tani Mentari. Program tersebut telah berhasil mewujudkan Desa Genteng menjadi desa binaan yang produktif dan berkelanjutan, yaitu membuat produk snack berbahan dasar terong berupa Cheese Stick Terong yang diberi brand Citrong. Tim dalam program ini dinamai Citrong Team. Kelompok Wanita Tani Mentari berfokus di bidang produksi dan IAAS LC Unpad berfokus di bidang pengembangan, pemasaran dan desain.

Satu buah terong dengan berat 220-260gr dapat menghasilkan Citrong sebanyak 1 $\mathrm{kg}$, setara dengan \pm 12 pcs Citrong untuk $100 \mathrm{gr}$ dan \pm 25 pcs Citrong untuk $50 \mathrm{gr}$. Citrong memiliki lima varian rasa yang terdiri dari rasa original, cabe diamisan (pedas manis), jeruk dicabean (pedas jeruk), dikejuan (keju), dan choconamon (cokelat). Citrong memiliki kemasan yang bervariasi yaitu Citrong Ready Stock dengan harga Rp 7.000 untuk 50gr (seluruh varian rasa) dan Rp 10.000 untuk 100gr (seluruh varian rasa), Citrong Edisi Boboran dengan harga Rp 10.000 (seluruh varian rasa), Citrong Edisi Congraduation dengan harga Rp 15.000 (seluruh varian rasa), Citrong Limited Edition dengan harga Rp 12.000 (varian rasa Choconamon) serta Citrong Edisi Natal dan Tahun Baru dengan harga Rp 10.000 (seluruh varian rasa). Strategi yang dilakukan Citrong Team dalam menjual Citrong, yaitu melalui social media (instagram, line whatsapp, facebook), personnal selling (acara di kampus dan desa), dan partnership (reseller, acara kampus, kantin).

Gambar 1. Jumlah Produksi dan Penjualan Citrong Tahun 2018-2019



Keterangan: *) Produksi dan Penjualan Citrong Ready Stock

**) Produksi dan Penjualan Citrong Edisi Boboran

Berdasarkan Gambar 1 menunjukkan bahwa Citrong memiliki tingkat produksi dan penjualan yang belum stabil. Apabila dibandingkan dengan tahun 2018, pada tahun 2019 memiliki tingkat penjualan yang jauh lebih banyak. Hal ini menunjukkan bahwa adanya ketertarikan konsumen akan keunikan Citrong seperti yang diutarakan oleh Vioren, yaitu Ceesna Citrong (konsumen) yang paling sering membeli Citrong secara berulang-ulang sekaligus sebagai salah satu reseller Citrong yang menyatakan bahwa: 
"Saya sering beli Citrong karena rasanya yang enak, unik (belum ada yang jual), dan
bikin ketagihan. Selain bisa buat cemilan, bisa juga dijadikan teman nasi dan sangat
membantu anak kosan jika sedang tidak ada stock makanan. Alasan ingin menjadi
reseller, awalnya supaya ada stock cemilan di kosan dan untuk oleh-oleh orang tua
jika saya mudik. Lalu mamah saya mencoba mencicipinya dan memberikan kepada
orang-orang di daerahnya, ternyata respon mereka baik. Jadi, saya memutuskan
untuk menjadi reseller Citrong. Lumayan untuk menambah penghasilan uang jajan". ${ }^{1}$

Perkembangan UMKM khususnya pada sektor industri makanan tidak selamanya berjalan dengan lancar, tentunya akan ada kendala yang selalu dihadapi oleh seseorang yang sedang merintis usahanya. Hal tersebut pun dirasakan oleh Sufi sebagai Project Officer Citrong Team 2019 dan Entin Wartini sebagai Staff of Production Citrong Team 2019 sekaligus sebagai Ketua Kelompok Wanita Tani Mentari. Kondisi tersebut ditunjang oleh pernyataan Sufi yang menyatakan bahwa:

"Kendala yang dirasakan oleh Citrong Team 2019 pada program Village Concept Project adalah pada kegiatan pemasaran. Selama 2,5 tahun ini, Kelompok Wanita Tani Mentari belum dapat memasarkan Citrong secara mandiri dimana Kelompok Wanita Tani Mentari hanya bisa melakukan kegiatan produksi pembuatan Citrong saja. Jadi yang ditakutkan ialah tidak berlanjutnya usaha Citrong apabila IAAS LC Unpad tidak lagi membinanya." ${ }^{2}$

Sedangkan Entin Wartini memberi pernyataan bahwa:

"Kendala yang dirasakan oleh ibu-ibu Kelompok Wanita Tani Mentari, adalah pada kegaiatan pemasaran. Kami belum dapat memasarkan Citrong secara mandiri. Pernah coba jual di desa tapi gagal, karena harganya terlalu mahal mungkin segmen pasarnya berbeda. ${ }^{\prime \prime 3}$

Berdasarkan uraian di atas, peneliti tertarik untuk meneliti bagaimana strategi pemasaran usaha mikro Citrong Kelompok Wanita Tani Mentari agar bisa mandiri apabila sudah tidak dibina lagi oleh IAAS LC Unpad.

\section{METODE PENELITIAN}

Objek dalam penelitian ini adalah strategi pemasaran usaha mikro Citrong (Cheese Stick Terong) Kelompok Wanita Tani binaan IAAS LC Unpad. Desain dalam penelitian ini yaitu desain kualitatif. Metode yang dilakukan dalam penelitian ini yaitu studi kasus. Penelitian ini dilakukan di pengolahan Citrong yang bertempat di Di Desa Genteng, Kecamatan Sukasari, Kabupaten Sumedang. Peneliti memanfaatkan informan agar dalam waktu yang relatif singkat banyak informasi yang terjangkau. Informan yang dipilih dalam memberikan informasi adalah Project Officer Citrong, Finance Citrong Team, Head of Marketing Citrong Team, Head of Partnership Citrong Team, Head of Design Citrong Team, Head of Production Citrong Team, Staff of Production Citrong Team, Reseller Citrong, Petani terong Desa Genteng, dan Ketua Taruna Karya Dusun Pasirkaliki Desa Genteng.

\section{HASIL DAN PEMBAHASAN Keadaan Umum Tempat Penelitian}

\footnotetext{
${ }^{1}$ Wawancara dengan Vioren (19 tahun), sebagai Ceesna Citrong dan Reseller Citrong, pada tanggal 25 Agustus 2019

${ }^{2}$ Wawancara dengan Sufi (20 tahun), sebagai Project Officer Citrong Team 2019, pada tanggal 24 Agustus 2019

${ }^{3}$ Wawancara dengan Entin Wartini (45 tahun), sebagai Staff of Production Citrong Team 2019 dan Ketua Kelompok Wanita Tani Mentari, pada tanggal 31 Agustus 2019
} 
Desa Genteng merupakan salah satu dari 7 desa di wilayah Kecamatan Sukasari, Kabupaten Sumedang, Jawa Barat. Berdasarkan data BPS Kabupaten Sumedang tahun 2018, jumlah penduduk Desa Genteng berjumlah 5.971 dimana 2.509 orang diantaranya sebagian besar bekerja pada sektor pertanian. Kondisi tersebut menunjukkan bahwa peningkatan pendapatan masyarakat Desa Genteng diperoleh melalui sektor pertanian. Hal ini terkait dengan kondisi lahannya yang berada di ketinggian 800-1200 mdpl dengan suhu udara yang sejuk $18-22^{\circ} \mathrm{C}$, menjadikan Desa Genteng didominasi oleh lahan ladang yang ditanami berbagai jenis sayuran. Adapun jenis komoditas sayuran yang banyak dibudidayakan oleh petani di Desa Genteng diantaranya, yaitu tomat, cabe merah, kubis, kentang, dan terong.

\section{Profil IAAS LC Unpad sebagai Pembina Kelompok Wanita Tani Mentari}

International Association of Students in Agricultural and Related Sciences (IAAS) adalah sebuah organisasi perkumpulan mahasiswa pertanian dan ilmu-ilmu terkait dari seluruh dunia yang didirikan pada tahun 1957 di Tunisia dan bermarkas di Leuven, Belgia. IAAS beranggotakan lebih dari 46 negara dari benua Afrika, Asia, Eropa, dan Amerika. Indonesia telah diterima menjadi anggota penuh IAAS sejak tahun 1992. Saat ini IAAS beranggotakan 52 negara dari benua Afrika, Asia, Eropa, dan Amerika Latin. Di Indonesia sendiri, IAAS terdapat di delapan universitas, salah satunya IAAS LC Unpad. Kegiatan yang dimiliki IAAS LC Unpad adalah Village Concept Project yang merupakan salah satu program dari Project Departement dalam meningkatkan pengembangan desa di bidang pertanian melalui kegiatan pemberdayaan masyarakat desa. Program tersebut bertujuan untuk menggali dan mengoptimalkan potensi-potensi yang dimiliki desa tersebut.

\section{Profil Kelompok Wanita Tani Mentari}

Kelompok Wanita Tani Mentari merupakan kelompok organisasi yang beranggotakan perempuan yang sebagian besar adalah istri dari petani di Desa Genteng. Kelompok Wanita Tani Mentari dibentuk pada tahun 2008 sebagai suatu wadah organisasi yang diharapakan bisa memberikan kontribusi yang baik bagi Desa Genteng. Terbentuknya organisasi tersebut berawal dari kebiasan perkumpulan kelompok arisan desa dan kelompok simpan pinjam perempuan. Filosofi penamaan Kelompok Wanita Tani "Mentari" adalah seperti sinar mentari yang memiliki manfaat bagi setiap orang. Penggunaan nama tersebut diharapkan memberi manfaat bagi setiap anggota dan menjadi aspirasi untuk anggotanya maupun masyarakat lain. Kegiatan yang sedang Kelompok Wanita Tani Mentari lakukan saat adalah (1) produksi Citrong; (2) Produksi dan Penjualan Dodol Tomat; (3) Program KRPL (Kawasan Rumah Pangan Lestari).

\section{Faktor Internal Usaha Mikro Citrong}

\section{Faktor Sumber Daya Manusia}

Kolaborasi yang terjalin antara IAAS LC Unpad dengan Kelompok Wanita Tani Mentari adalah sebagi mitra bisnis yang bersifat kekeluargaan. Tim kolaborasi pada program Village Concept Project ini dinamai Citrong Team. Terdapat 19 anggota IAAS LC Unpad yang berfokus di bidang pengembangan, pemasaran, dan desain serta 6 anggota Kelompok Wanita Tani Mentari yang berfokus di bidang produksi. Pembagian kerja Kelompok Wanita Tani Mentari saat produksi Citrong adalah:

1. Belanja dan pendistribusian Citrong ke Jatinangor: Erni;

2. Mengulen hingga menggoreng: Wiwin, Rita, Enok;

3. Membuat varian bumbu rasa: Entin;

4. Menimbang dan mengemas: Entin Wartini;

5. Menggunting stiker, menempelkan stiker pada kemasan dan men-cap expired datepada kemasan: Rita; 
6. Men-sealer kemasan: Erni.

\section{Faktor Produksi}

Produksi Citrong memiliki jadwal yang fleksibel, yaitu tergantung permintaan dari Marketing Team (IAAS LC Unpad). Biasanya dilakukan pada hari rabu atau kamis pukul 08.00 WIB. Pembuatan Citrong memiliki estimasi waktu 3 jam untuk produksi dengan jumlah yang sedikit, yaitu kurang dari $3 \mathrm{~kg}$ dan 5 hingga 6 jam untuk produksi dengan jumlah yang banyak, yaitu lebih dari $3 \mathrm{~kg}$. Bahan baku pembuatan Citrong terdiri dari: (1) Bahan baku utama, yaitu terong yang diperoleh dari petani terong di Desa Genteng atau dari hasil panen Kebun Bibit Kelompok Wanita Tani Mentari; (2) Bahan baku pembantun, yaitu tepung, keju, telur dan lain-lain yang diperoleh dari Pasar Tanjungsari; (3) Bahan Kemasan, yaitu standing pouch dan stiker yang saat ini masih dikelola oleh IAAS LC Unpad.Tahun ini Kelompok Wanita Tani Mentari sebagai Staff of Production sudah memiliki Standar Operasional Prosedur (SOP) berupa formula baru yang menghasilkan rasa Citrong menjadi lebih enak dan renyah. Adapun langkah kerja dalam proses produksi Citrong adalah:

1. Mengupas kulit terong;

2. Menghaluskan terong menggunakan blender;

3. Mencampurkan seluruh bahan baku (terong yang sudah dihaluskan, keju, tepung, telur, dan lain-lain) untuk diaduk kedalam baskom hingga kalis;

4. Menggiling adonan menggunakan noodle maker;

5. Menggoreng adonan hingga matang;

6. Membuat varian bumbu rasa;

7. Menggunting stiker dan men-cap expired date pada stiker dengan alat stample manual;

8. Menimbang Citrong dan dimasukkan kedalam kemasan;

9. Men-sealer kemasan hingga rapat;

10. Menghitung kembali Citrong yang sudah diproduksi sesuai dengan pemesanan.

\section{Faktor Keuangan}

Modal yang didapat Kelompok Wanita Tani Mentari dalam memproduksi Citrong diperoleh dari hasil keuntungan penjualan Citrong pada periode sebelumnya, uang kas Kelompok Wanita Mentari dan meminjam uang milik Entin Wartini (Ketua Kelompok Wanita Tani Mentari). Sistem keuntungan yang diterapkan antara IAAS LC Unpad dengan Kelompok Wanita Tani Mentari, yaitu bagi hasil untuk setiap kali produksi berjumlah $80 \%$ untuk Kelompok Wanita Tani Mentari dan 20\% untuk IAAS LC Unpad. Keuntungan yang diperoleh IAAS LC Unpad digunakan untuk membeli kebutuhan penjualan Citrong seperti membeli kantung plastik, bubble wrap, dan promosi media partner. Adapun keuntungan yang diperoleh Kelompok Wanita Tani Mentari digunakan untuk membeli alat-alat produksi Citrong. Pembukuan keuangan Kelompok Wanita Tani Mentari dikelola oleh Entin Wartini sebagai Ketua Kelompok Wanita Tani Mentari. Namun pembukuan tersebut belum dilakukan secara rutin, karena Kelompok Wanita Tani Mentari belum mengerti tentang pentingnya pembukuan dalam suatu usaha.

\section{Faktor Pemasaran}

\section{Produk (Product)}

Mengenai produk, Citrong memiliki lima varian rasa yang terdiri dari rasa original, cabe diamisan (pedas manis), jeruk dicabean (pedas jeruk), dan (keju). Lalu terdapat satu varian rasa baru yang launching pada bulan Oktober 2019, yaitu choconamon (cokelat). Citrong memiliki kemasan yang bervariasi sesuai dengan edisi, yaitu Citrong Ready Stock, Citrong Edisi Boboran, Citrong Edisi Congraduation, Citrong Limited Edition, dan Citrong Edisi Natal dan Tahun Baru. Mengenai kualitas produk, sejak tahun 2017 Citrong sudah memiliki 
nutrition fact dan expired date. Adapun kendala di tahun ialah dalam hal legalitas, yaitu pembuatan izin PIRT yang masih belum terlaksana. Hal tersebut terjadi karena keterlambatan Citrong Team 2019 saat mendaftar ke Dinas Kesehatan Sumedang di bulan April 2019 dan penundaan waktu pembuatan izin PIRT oleh Dinas Kesehatan Sumedang di tahun November 2019. Mengenai daya tarik konsumen, bahan baku terong dan keterlibatan Kelompok Wanita Tani Mentari menjadi salah satu daya tarik konsumen untuk membeli Citrong.

\section{Harga (Price)}

Penetapan harga jual Citrong menggunakan dua strategi, yaitu penetapan harga berdasarkan keinginan, yaitu price sensitivity method dan penetapan harga berdasarkan harga jual, yaitu cost-plus pricing method. Price sensitivity method adalah penetapan harga berupa persepsi konsumen terhadap nilai produk yang diterima, apakah sebanding atau tidak (Secapramana, 2000). Sedangkan cost-plus pricing method adalah penetapan harga jual per-unit berdasarkan jumlah biaya per-unit ditambah jumlah tertentu sebagai laba (Secapramana, 2000). Pengaruh harga jual Citrong terhadap kepuasan konsumen saat ini memiliki respon yang cukup baik. Banyak konsumen yang menyatakan bahwa harga jual Citrong sudah sebanding dengan nilai produk yang ditawarkan. Namun terdapat kendala, dimana harga Citrong belum menjangkau seluruh segmen konsumen. Hal tersebut mengakibatkan Kelompok Wanita Tani Mentari kesulitan untuk bisa menjual Citrong secara mandiri.

\section{Promosi (Promotion)}

Citrong Team 2019 menjadikan social media sebagai media promosi Citrong yang paling cepat dalam menyampaikan informasi kepada konsumen. Media yang digunakan, yaitu akun instagram yang dikelola oleh Design Citrong Team 2019 dan akun line yang dikelola oleh Marketing Citrong Team 2019. Adapun social media yang digunakan oleh Kelompok Wanita Tani Mentari masih sangat terbatas. Hanya terdapat dua anggota Kelompok Wanita Tani Mentari yang paham dalam penggunaan teknolgi tersebut, yaitu Entin dan Erni yang mempromosikan Citrong melalui akun whatsapp dan facebook pribadi. Hasil promosi tersebut memiliki respon yang kurang baik, karena Kelompok Wanita Tani Mentari tidak memiliki saluran untuk menjual Citrong ke konsumen khususnya anak muda.

Citrong Team 2019 menjadikan strategi personnal selling sebagai strategi promosi yang paling efektif dalam memberikan informasi kepada konsumen secara langsung seperti mengikuti acara bazar kampus di Faperta Unpad, acara bazar IAAS Summit di Jakarta, acara bazar Dispora Kota Bandung, dan lain-lain. Kelompok Wanita Tani Mentari pun cukup aktif dalam mempromosikan Citrong secara langsung seperti mengikuti acara bazar 17 agustus di Desa Genteng, acara voli antar desa, dan acara bazar dinas UMKM Sumedang.

Citrong Team 2019 menjadikan strategi partnership sebagai strategi promosi yang paling mudah guna memperluas branding Citrong. Mitra Citrong Team saat ini adalah reseller, Kantin, dan acara kampus. Mengenai reseller, Citrong sudah memiliki reseller berjumlah 6 orang. Setiap reseller diberi fasilitas berupa panduan "Booklet reseller Citrong". Panduan tersebut berisi informasi lengkap mengenai Citrong (sejarah, struktur organisasi, keunggulan, cara mempromosikan dan menjual Citrong). Hal tersebut bertujuan agar reseller memiliki pemahaman lebih tentang Citrong yang tentunya akan memudahkan mereka saat menjual Citrong.

\section{Distribusi (Place)}

Alur distribusi Citrong terdiri dari: 
- Kelompok Wanita Tani Mentari ke IAAS LC Unpad: diantar oleh salah satu anggota dari Kelompok Wanita Tani Mentari menggunakan sepedah motor. Jarak yang ditempuh sekitar $12 \mathrm{KM}$ dengan estimasi waktu 45 menit;

- Citrong Team 2019 ke Konsumen Akhir: konsumen akhir memesan Citrong melalui akun line Citrong. Kemudian, Citrong akan diantar oleh Staff of Marketing Citrong Team 2019. Sedangkan untuk Citrong ke konsumen akhir yang berada di luar kota, yaitu pengirimannya menggunakan kurir TIKI Jatinangor;

- Citrong Team 2019 ke Reseller. reseller memesan Citrong melalui akun line pribadi dari Staff of Partnership Citrong Team 2019. Kemudian, akan diantar oleh Staff of Partnership Citrong;

- Citrong Team 2019 ke Kantin: Staff of Partnership Citrong Team 2019 mengirim Citrong kepada penjaga Kantin dengan jumlah yang banyak;

- Citrong Team 2019 ke Acara Kampus: Staff of Partnership Citrong Team 2019 dan panita acara membuat kesepakatan perjanjian MOU dalam hal pengiriman Citrong.

\section{Faktor Eksternal Usaha Mikro Citrong}

Faktor Sosial Budaya

Kebiasaan anak muda dalam mengkonsumsi snack memberi peluang besar bagi para pelaku usaha snack dalam mengembangkan usahanya. Selain itu, makanan merupakan kebutuhan dasar bagi manusia, hal ini pun menjadi alasan bahwa usaha kuliner salah satunya ialah snack selalu menguntungkan untuk dijalankan

\section{Faktor Teknologi}

Dunia digital menjadi prioritas terpenting bagi seluruh aktivitas manusia, termasuk dalam hal bisnis. Pesatnya perkembangan teknologi tersebut berimbas pada dunia pemasaran. Tren pemasaran di dunia beralih dari konvensional (offline) menjadi digital (online). Digital marketing adalah kegiatan promosi dan pencarian pasar secara online (Wardhana, 2015). Pemanfaatan konsep pemasaran berbasis digital marketing memberikan harapan bagi UMKM untuk berkembang menjadi pusat kekuatan ekonomi (Purwana, 2017).

\section{Faktor Pesaing}

Banyaknya jumlah pelaku usaha snack di pasaran berdampak pada tingginya persaingan dalam memasarkan produknya masing-masing. Tekanan persaingan semakin bertambah, ketika harga produk pengganti relatif lebih terjangkau. Hal tersebut menjadikan pertimbangan dalam membeli snack khususnya bagi anak muda dengan harga yang cukup terjangkau.

\section{Faktor Lembaga Pendukung}

1. Perguruan Tinggi

- Unpad memiliki fakultas dan jurusan yang terbilang lengkap, yaitu 16 fakultas dengan total 127 jurusan;

- Unpad memiliki unit inkubator bisnis (Oorange) yang bekerja sama dengan Pemerintah Kabupaten Sumedang, Bank Rakyat Indonesia, dan PT. Digital Tracking dalam mengembangkan potensi kewirausahaan di Kabupaten Sumedang;

- Jatinangor menjadi kawasan pendidikan dengan dibangunnya empat perguruan tinggi, yaitu Unpad, ITB, Ikopin, dan IPDN;

- Citrong merupakan produk kolaborasi milik IAAS LC Unpad yang berada di bawah induk dari IAAS Indonesia. Terdapat delapan universitas yang bergabung dengan IAAS Indonesia. 
2. Karang Taruna

Karang Taruna sebagai generasi muda memiliki peluang yang besar terhadap pembangunan ekonomi desa. Sebagaimana menurut Puspitasari (2015) bahwa:

- Karang Taruna memiliki beragam inisiatif yang dapat memberikan kontribusi positif dalam proses perubahan sosial;

- Karang Taruna menjadi bagian dari agen yang secara kreatif dan inovatif mampu memanfaatkan berbagai macam peluang;

- Potensi Karang Taruna dapat dioptimalkan melalui kewirausahaan sesuai minat dan bakat pemuda serta potensi daerah.

3. Pemerintah

Pemerintah desa merupakan lembaga yang memiliki tugas untuk menyelanggarakan pemerintahan desa, melaksanakan pembagunan desa, pembinaan kemasyarakatan desa, dan pemberdayaan masyarakat desa. Begitupun dengan pemerintah Desa Genteng kepada masyarakatnya, akan tetapi kegiatan program-program Desa Genteng terhadap UMKM tidak menjadi prioritas utama saat ini.

Berbeda dengan pemerintah Provinsi Jawa Barat yang memberi dukungan positif terhadap UMKM. Sumedang Creatice Center merupakan bantuan dari Pemerintah Provinsi untuk pembangunan gedung kreatif sebagai wadah komunitas kreatif skala kota. Gedung tersebut membawahi 16 sub sektor ekonomi kreatif. Salah satu kegiatan yang sudah dilakukan oleh Sumedang Creative Center, yaitu bantuan dan informasi izin PIRT.

4. Komunitas Bisnis

Komunitas bisnis yang sedang berkembang pesat di Jatinangor adalah The Local Enablers yang berlokasi di Rumah Kolaborasi (Apartmen Skyland). Komunitas ini digerakkan oleh Dr. Dwi Purnomo yang bergerak di bidang pendidikan dan pemberdayaan masyarakat untuk membantu UMKM dalam mengembangkan produk.

\section{Analisis Matriks IFAS dan EFAS}

Tabel 2. Analisis Matriks IFAS Usaha Mikro Citrong

\begin{tabular}{|c|c|c|c|c|}
\hline & Faktor-Faktor Internal & Bobot & Rating & $\begin{array}{c}\text { Skor } \\
\text { (Bobot } \\
\mathbf{x} \\
\text { Rating) }\end{array}$ \\
\hline \multicolumn{5}{|c|}{ Kekuatan (strengths) } \\
\hline S1 & Kelompok Wanita Tani Mentari sudah memiliki tim yang kompak & 0,054 & 3 & 0,162 \\
\hline $\mathrm{S} 2$ & $\begin{array}{l}\text { Memiliki formula baru dengan hasil rasa yang lebih enak dan } \\
\text { renyah }\end{array}$ & 0,054 & 4 & 0,216 \\
\hline S3 & Alat produksi Citrong sudah lengkap & 0,054 & 2 & 0,108 \\
\hline S4 & Bahan baku Terong selalu tersedia & 0,054 & 4 & 0,216 \\
\hline S5 & Memiliki kemasan yang bervariasi sesuai dengan edisi & 0,094 & 3 & 0,282 \\
\hline S6 & $\begin{array}{l}\text { Produk Cheese Stick pertama yang terbuat dari bahan baku } \\
\text { Terong }\end{array}$ & 0,054 & 4 & 0,216 \\
\hline S7 & Produk hasil program pemberdayaan desa & 0,054 & 4 & 0,216 \\
\hline \multicolumn{5}{|c|}{ Kelemahan (weakness) } \\
\hline W1 & $\begin{array}{l}\text { Kelompok Wanita Tani Mentari belum menguasai keterampilan } \\
\text { dalam bidang pemasaran }\end{array}$ & 0,054 & 2 & 0,108 \\
\hline W2 & Kemasan dan stiker masih dikelola oleh IAAS LC Unpad & 0,090 & 2 & 0,18 \\
\hline W3 & Menggunakan alat stample expired date manual & 0,094 & 2 & 0,188 \\
\hline \multicolumn{2}{|r|}{ Total } & & & 2,3 \\
\hline
\end{tabular}


Berdasarkan analisis matriks IFAS pada Tabel 2 diperoleh jumlah total pembobotan skor matriks evaluasi faktor internal sebesar 2,3. Hal tersebut menunjukkan bahwa usaha mikro Citrong berada di posisi internal rata-rata, artinya belum bisa memanfaatkan kekuatan yang dimiliki dengan baik.

Tabel 3. Analisis Matriks EFAS Usaha Mikro Citrong

\begin{tabular}{|c|c|c|c|c|}
\hline & Faktor-Faktor Eksternal & Bobot & Rating & $\begin{array}{l}\text { Skor } \\
\text { (Bobot x } \\
\text { Rating) }\end{array}$ \\
\hline \multicolumn{5}{|c|}{ Peluang (opportunities) } \\
\hline $\mathrm{O} 1$ & Kebiasaan anak muda dalam mengkonsumsi snack & 0,067 & 4 & 0,268 \\
\hline $\mathrm{O} 2$ & $\begin{array}{l}\text { Digital Marketing memberikan dampak positif bagi } \\
\text { perkembangan UMKM }\end{array}$ & 0,049 & 4 & 0,196 \\
\hline $\mathrm{O} 3$ & $\begin{array}{l}\text { Banyaknya mahasiwa Unpad (16 fakultas, } 127 \\
\text { jurusan) }\end{array}$ & 0,067 & 3 & 0,201 \\
\hline $\mathrm{O} 4$ & Unpad memiliki unit inkubator bisnis (Oorange) & 0,082 & 3 & 0,246 \\
\hline O5 & $\begin{array}{l}\text { Jatinangor menjadi kawasan pendidikan (Unpad, } \\
\text { ITB, Ikopin, IPDN) }\end{array}$ & 0,060 & 3 & 0,18 \\
\hline O6 & $\begin{array}{l}\text { Terdapat delapan universitas yang bergabung } \\
\text { dengan IAAS Indonesia }\end{array}$ & 0,063 & 3 & 0,189 \\
\hline $\mathrm{O7}$ & Karang Taruna Desa & 0,108 & 4 & 0,432 \\
\hline $\mathrm{O} 8$ & $\begin{array}{l}\text { Komunitas Sumedang Creative Center menyediakan } \\
\text { bantuan pembuatan izin PIRT } \\
\text { Komunitas The Local Enablers sebagai komunitas }\end{array}$ & 0,101 & 3 & 0,303 \\
\hline 09 & $\begin{array}{l}\text { yang bergerak di bidang pendidikan dan } \\
\text { pemberdayaan masyarakat }\end{array}$ & 0,093 & 3 & 0,279 \\
\hline \multicolumn{5}{|c|}{ Ancaman (threats) } \\
\hline T1 & $\begin{array}{l}\text { Kurangnya loyalitas konsumen, karena adanya } \\
\text { produk pengganti yang lebih murah }\end{array}$ & 0,108 & 2 & 0,216 \\
\hline T2 & $\begin{array}{l}\text { Sedikitnya jumlah mitra yang bekerjasama dengan } \\
\text { Citrong }\end{array}$ & 0,078 & 2 & 0,156 \\
\hline T3 & $\begin{array}{l}\text { Kurangnya dukungan dari pemerintah desa Genteng } \\
\text { terhadap UMKM }\end{array}$ & 0,123 & 3 & 0,369 \\
\hline \multicolumn{4}{|c|}{ Total } & 3,0 \\
\hline
\end{tabular}

Berdasarkan analisis matriks EFAS pada Tabel 3 diperoleh jumlah total pembobotan skor matriks evaluasi faktor eksternal sebesar 3,0. Hal tersebut menunjukkan bahwa usaha mikro Citrong berada di posisi eksternal yang kuat, artinya mampu memanfaatkan peluang secara optimal.

\section{Analisis Matriks IE}

Gabungan matriks IFAS dan EFAS yang telah dievaluasi menghasilkan matriks IE yang memposisikan usaha mikro Citrong ke dalam matriks yang terdiri atas sembilan sel. Matriks IE ini terdiri atas dua dimensi, yaitu: total skor dari IFAS pada sumbu $X$ dengan total nilai bobot sebesar 2,3 dan total skor dari EFAS pada sumbu $Y$ dengan total nilai bobot sebesar 3,0. Berdasarkan Tabel 26, usaha mikro Citrong berada pada sel II yang 
menunjukkan jenis strategi Growth and Build (tumbuh dan kembangkan). Strategi-strategi yang cocok bagi usaha mikro Citrong adalah strategi intensif atau strategi terintegrasi.

Tabel 4. Matriks IE Usaha Mikro Citrong

\begin{tabular}{|c|c|c|c|c|}
\hline & & \multicolumn{3}{|c|}{ Total Skor IFAS } \\
\hline \multirow{4}{*}{$\begin{array}{c}\text { Total } \\
\text { Skor } \\
\text { EFAS }\end{array}$} & \multirow{4}{*}{$\begin{array}{c}\text { Tinggi } \\
(3,0-4,0) \\
\text { Sedang } \\
(2,0-2,99) \\
\text { Rendah } \\
(10-199)\end{array}$} & $\begin{array}{c}\text { Kuat } \\
(3,0-4,0)\end{array}$ & $\begin{array}{c}\text { Sedang } \\
(2,0-2,99)\end{array}$ & $\begin{array}{c}\text { Lemah } \\
(1,0-1,99)\end{array}$ \\
\hline & & I & II & III \\
\hline & & IV & V & VI \\
\hline & & VII & VIII & IX \\
\hline
\end{tabular}

\section{Analisis Matriks SWOT}

Penyusunan matriks SWOT pada Tabel 5 dilakukan untuk mengidentifikasi faktor internal maupun eksternal usaha mikro Citrong secara sistematis dalam merumuskan alternatif strategi.

Tabel 5. Analisis Matriks SWOT Usaha Mikro Citrong

Faktor

Internal

Kekuatan (S)

S1-S7

Faktor

Eksternal

\begin{tabular}{ccc} 
Eksternal & Strategi SO: & Strategi wo: \\
Peluang (0) & S1, O4, O8, O9 & W1, W2, W4, O2, O4, O8, \\
& S2, S3, S4, O1 & O9 \\
O1-09 & S5, S6, S7, O3, O5, & W5, O8 \\
& & W3, W8, O3, O5, O6, O7, O8 \\
\hline \multirow{2}{*}{ Ancaman (T) } & Strategi ST: & Strategi WT: \\
T1-T3 & S4, S6, S7, T3 & W6, T1 \\
& & W8, T2
\end{tabular}

Kelemahan (W)

W1-W8

Hasil altermatif strategi tersebut akan memberikan pertimbangan ke depan yang akan diimplementasikan oleh Citrong Team 2019 maupun Citrong Team 2020 agar diperolehnya strategi pemasaran untuk mengembangkan usaha mikro Citrong bagi Kelompok Wanita Tani. Berdasarkan hasil analisis matriks SWOT, alternatif strategi yang dapat diterapkan pada usaha mikro Citrong adalah pada Tabel 6. 
Tabel 6. Alternatif Strategi Usaha Mikro Citrong
Alternatif Strategi
Penjelasan

Strategi SO

$(\mathrm{S} 1,04,08,09)$

Bergabung dalam komunitas bisnis

(S2, S3, S4, O1) Menjaga loyalitas konsumen dengan menjaga kualitas produk

(S5, S6, S7, 03, 05, 06)

Meningkatkan pangsa pasar dengan menciptakan strategi promosi yang menarik

Strategi WO (W1, W2, W4, O2, 04, 08, 09)

Mengikuti pelatihan digital marketing dan keuangan

(W2, 07)

Mengelola kemasan dan stiker secara mandiri

(W5, 08)

Membuat sertifikasi izin PIRT
Kelompok Wanita Tani Mentari dapat bergabung pada komunitas bisnis Oorange, Sumedang Creative Center, dan The Local Enablers. Strategi tersebut bertujuan untuk mempermudah Kelompok Wanita Tani Mentari dalam mengembangkan usaha mikro Citrong khusunya dalam hal pemasaran. Salah satu manfaat bergabung di komunitas bisnis adalah merperluas jaringan bisnis berupa bantuan pemasaran dalam meningkatkan penjualan. Strategi ini juga memiliki kesesuaian dengan matriks IE, yaitu strategi intensif: penetrasi pasar dan pengembangan pasar.

Kelompok Wanita Tani Mentari harus menjaga kualitas produk Citrong sesuai SOP yang dimiliki. Strategi tersebut bertujuan untuk mempertahankan kepuasan konsumen. Jika Kelompok Wanita Tani Mentari dapat melakukannya secara konsisten, maka konsumen akan tetap loyal dalam membeli produk Citrong. Strategi ini juga memiliki kesesuaian dengan matriks $\mathrm{IE}$, yaitu strategi intensif: pengembangan produk

Kelompok Wanita Tani Mentari dapat meningkatkan dan memperluas pasar, yaitu mahasiwa Unpad, ITB, IKOPIN, IPDN, dan anggota IAAS dengan menciptakan startegi promosi yang menarik. Salah satunya dengan cara menceritakan keunggulan yang dimiliki produk Citrong, yaitu (1) kemasan yang bervariasi sesuai dengan edisi, (2) produk Cheese Stick pertama yang terbuat dari bahan baku terong, dan (3) produk hasil program pemberdayaan desa. Strategi tersebut bertujuan untuk menarik konsumen dalam membeli produk Citrong. Strategi ini juga memiliki kesesuaian dengan matriks $\mathrm{IE}$, yaitu strategi intensif: penetrasi pasar dan pengembangan pasar.

Kelompok Wanita Tani Mentari dapat mengikuti pelatihan digital marketing dan keuangan yang diselenggarkan oleh inkubator bisnis Oorange, Sumedang Creative Center, dan The Local Enablers. Strategi tersebut bertujuan agar Kelompok Wanita Tani Mentari dapat memasarkan Citrong melalui media sosial, membeli kebutuhan produksi yaitu kemasan secara online dan memiliki pembukuan yang tersusun. Pelatihan tersebut tentunya memberikan manfaat bagi Kelompok Wanita Tani Mentari dalam memasarkan Citrong secara mandiri. Strategi ini juga memiliki kesesuaian dengan matriks IE, yaitu strategi intensif: penetrasi pasar dan pengembangan pasar.

Kelompok Wanita Tani Mentari dapat meminta bantuan karang taruna desa untuk mencari tempat digital printing stiker yang berada di lingkungan Desa Genteng. Strategi tersebut bertujuan agar Kelompok Wanita Tani Mentari dapat mengelola kebutuhan bahan baku produksi secara mandiri. Strategi ini juga memiliki kesesuaian dengan matriks IE, yaitu strategi terintegrasi: integrasi ke belakang.

Kelompok Wanita Tani Mentari dapat meminta bantuan pada komunitas Sumedang Creative Center dalam pembuatan sertifikasi izin PIRT. Strategi tersebut bertujuan agar produk Citrong dapat dijual di toko offline seperti toko oleh-oleh dan toko snack. Strategi ini juga memiliki kesesuaian dengan matriks IE, yaitu strategi intensif: pengembangan produk.

(W3, W8, 03, 05, 06, Kelompok Wanita Tani Mentari dapat meningkatkan dan memperluas 
07, 08)

Memperbanyak mitra

Startegi ST

(S4, S6, S7, T3)

Menjadi produk

olahan snack khas

Desa Genteng

\section{Strategi WT}

(W6, T1)

Diversifikasi produk

dengan harga jual yang lebih murah

Membangun

kerjasama yang kuat dengan mitra yang sudah ada pasar dengan mengajak mahasiwa Unpad, ITB, IKOPIN, IPDN, anggota IAAS dan karang taruna Desa Genteng untuk menjadi mitra Citrong. Strategi tersebut bertujuan untuk mempermudah Kelompok Wanita Tani Mentari dalam membangun saluran penjualan yang lebih banyak. Selain itu, meningkatkan pendapatan Citrong yang dapat digunakan untuk membeli inventaris kebutuhan produksi yaitu alat expired date. Strategi ini juga memiliki kesesuaian dengan matriks IE, yaitu integrasi ke depan dan strategi intensif: penetrasi pasar ,dan pengembangan pasar.

Kelompok Wanita Tani Mentari harus selalu konsisten dalam memproduksi maupun menjual Citrong. Strategi tersebut bertujuan

agar produk Citrong yang berasal dari Desa Genteng bisa dikenal lebih luas. Selain itu, Citrong pun nantinya dapat menjadi produk olahan snack khas Desa Genteng. Hal tersebut memberikan kontribusi yang baik bagi Desa Genteng, salah satunya ialah pemerintah Desa Genteng. Strategi ini

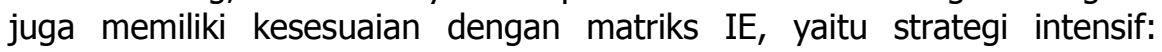
penetrasi pasar dan pengembangan pasar.

Kelompok Wanita Tani Mentari dapat mendiversifikasikan produk Citrong seperti: memiliki nama merk yang berbeda, menggunakan bahan baku yang lebih terjangkau, dan harga jual yang lebih murah. Strategi tersebut bertujuan untuk memperluas segmen pasar Citrong dalam meningkatkan penjualan. Strategi ini juga memiliki kesesuaian dengan matriks IE, yaitu strategi intensif: pengembangan produk.

Kelompok Wanita Tani Mentari dapat membangun kerjasama yang kuat dengan mitra yang sudah ada seperti reseller, kantin, dan acara kampus. Strategi tersebut bertujuan untuk menciptakan kerjasama yang saling menguntungkan dalam mempertahankan saluran kemitraan lebih lanjut. Strategi ini juga memiliki kesesuaian dengan matriks IE, yaitu integrasi ke depan.

\section{Analisis Matriks QSPM}

Hal terakhir yang harus dilakukan dalam perumusan strategi adalah pemilihan alternatif strategi terbaik dengan menggunakan analisis matriks QSPM yang didapatkan berdasarkan hasil analisis matriks SWOT. Strategi terbaik diperoleh dari hasil nilai TAS (Daya Tarik Total) tertinggi. Perumusan strategi ini hanya pada tahap formulasi strategi, sedangkan untuk tahap implementasi dan evaluasi strategi merupakan wewenang pihak Citrong Team 2019 maupun Citrong Team 2020. Berikut hasil analisis QSPM pada Tabel 7 yang menunjukkan hasil sepuluh strategi terbaik bagi usaha mikro Citrong, disusun berdasarkan hasil nilai TAS tertinggi hingga terendah. 
Tabel 7. Analisis Matriks QSPM Usaha Mikro Citrong Alternatif Strategi Total Nilai Daya Tarik

\begin{tabular}{lc}
\hline \multicolumn{1}{c}{ Alternatif Strategi } & $\begin{array}{c}\text { Total Nilai Daya Tarik } \\
\text { (TAS) }\end{array}$ \\
\hline Memperbanyak mitra & 4,917 \\
Meningkatkan pangsa pasar dengan menciptakan & \\
strategi promosi yang menarik & 4,863 \\
Diversifikasi produk dengan harga jual yang lebih & 4,527 \\
murah & \\
Mengikuti pelatihan digital marketing dan keuangan & 4,468 \\
Menjaga loyalitas konsumen dengan menjaga kualitas & 4,428 \\
produk & \\
Bergabung dalam komunitas bisnis & 4,174 \\
Membangun kerjasama yang kuat dengan mitra yang & 3,754 \\
sudah ada. & \\
Membuat sertifikasi izin PIRT & 3,736 \\
Menjadi produk olahan snack khas Desa Genteng & 3,386 \\
Mengelola kemasan dan stiker secara mandiri & 2,739 \\
\hline
\end{tabular}

\section{KESIMPULAN}

Usaha mikro Citrong berada pada sel II (posisi internal yang rata-rata dan posisi eksternal yang kuat) yang menunjukkan jenis strategi Growth and Build (tumbuh dan kembangkan). Jadi, strategi pemasaran yang dapat diterapkan adalah strategi intensif seperti penetrasi pasar, pengembangan pasar, dan pengembangan produk atau strategi terintegrasi seperti integrasi ke belakang, integrasi ke depan dan integrasi horizontal.

\section{DAFTAR PUSTAKA}

Aqil, M. (2018). Analisis Rantai Nilai dan Kontribusi Pendapatan Industri Kecil Pengolahan Terong Menjadi Cheesestick Terong. Jurnal IImiah Mahasiswa AGROINFO GALUH, Vol.5 No.1, Hal. 1001.

Badan Pusat Statistik Kabupaten Sumedang. (2018). Kecamatan Sukasari Dalam Angka 2018. Sumedang: Badan Pusat Statistik Kabupaten Sumedang.

Fakhrul, M. (2018). Implementasi Triple Helix Dalam Mendorong Pertumbuhan Industri Kreatif di Kota Malang Sebagai Upaya Peningkatan Daya Saing Untuk Menghadapi Masayarakat Ekonomi ASEAN. Jurnal Administrasi Bisnis, Vol. 55 No. 1, Hal. 61.

IAAS National Committe Indonesia 2018/2019. (2018). IAAS Indonesia. Dipetik September 2, 2019, dari http://iaas.or.id

Purwana, D. (2017). Pemanfaatan Digital Marketing Bagi Usaha UMKM diKelurahan Makala Sari, Duren Sawit. Jurnal Pemberdayaan Masyarakat Madani.

Puspitasari, D. C. (2015). Wirausaha Muda Membangun Desa: Dinamika Partisipasi Pembangunan Desa. Jurnal Studi Pemuda, Vol.4 No.2.

Wardhana, A. (2015). Strategi Digital Marketing dan Implikasinya pada Keunggulan Bersaing UKM di Indonesia.

Wilantara, R., \& Rully, I. (2016). Strategi dan Kebijakan Pengembangan UMKM. Bandung.

Wulandari, A., \& Sumodiningrat, G. (2016). Membangun Indonesia Dari Desa. Yogyakarta: Media Pressindo. 